\title{
Introduction: OUTPACE - Oligotrophy to Ultraoligotrophy PACific Experiment
}

\section{Thierry Moutin}

Mediterranean Institute of Oceanography (MIO), Aix Marseille Université, CNRS, Université de Toulon, IRD, OSU Pythéas, UM 110, 13288, Marseille, France

Correspondence: Thierry Moutin (thierry.moutin@mio.osupytheas.fr)

Published: 24 April 2019

"Le monde aurait pu être simple comme le ciel et la mer" - André Malraux

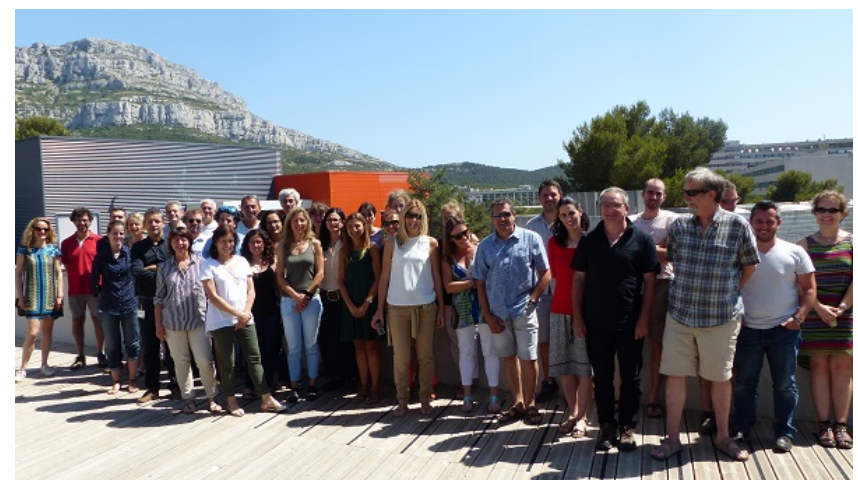

Biogeochemistry is a multidisciplinary natural science linking biological, geological, chemical, and physical sciences. Its purpose is to describe and understand the cycles of the elements on a large spatial scale. The study of the carbon cycle has become central in biogeochemistry due to the major role of atmospheric carbon dioxide in global warming. Understanding the cycles of the elements $(\mathrm{N}, \mathrm{P}, \mathrm{Si}, \mathrm{Fe})$, which control the production of organic carbon in the ocean's surface and subsequently its export to the deep ocean (i.e. the biological carbon pump), has become crucial as the Ocean controls atmospheric carbon dioxide for time scales of and above the decadal timescale.

I hope that this study, in the western tropical South Pacific, will be of interest to you.

Figure 1. The OUTPACE team preparing the OUTPACE cruise.

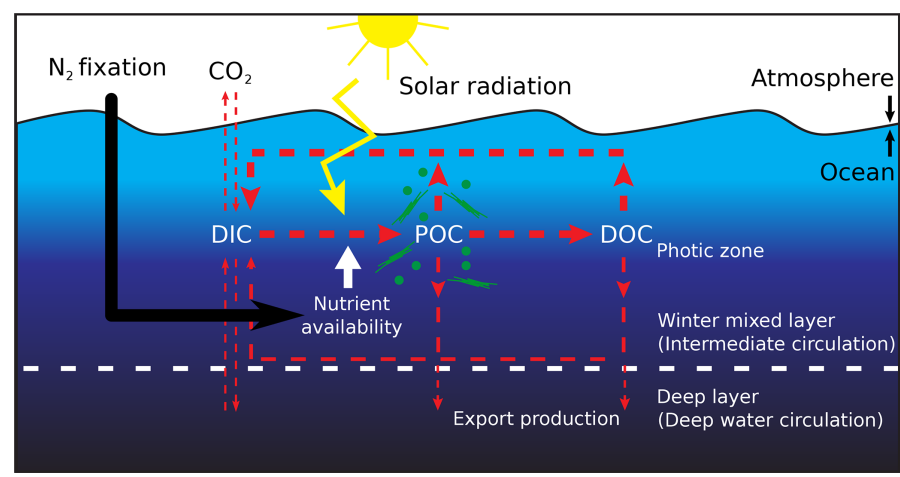

Figure 2. Major $\mathrm{C}$ fluxes of the biological carbon pump and main role of $\mathrm{N}_{2}$ fixation. DIC: dissolved inorganic $\mathrm{C}$; POC: particulate organic C; DOC: dissolved organic C. 